\title{
Designing Connected Health Interventions for Emerging Mobile Users
}

Aakash Ganju ${ }^{1}$, MD; Sumiti Saharan ${ }^{1}$, PhD; Alice Lin Fabiano ${ }^{2}$; Lily Lee ${ }^{1}, \mathrm{PhD}$

${ }^{1}$ Avegen Pte Ltd, Mumbai, India
${ }^{2}$ Johnson \& Johnson, New Brunswick, NJ, United States

Corresponding Author:

Aakash Ganju, MD

Avegen Pte Ltd

1103 Cliff Avenue

Glencroft, Hiranandani Gardens, Powai

Mumbai,

India

Phone: 91821195149

Email: aakash@avegenhealth.com

\section{Abstract}

Background: While mobile technologies have unlocked opportunities to address health care access and affordability gaps, billions of emerging mobile users are yet to reap the benefits of connected health.

Objective: We studied data enabled mobile phone ownership and behaviors amongst low income young Indian families. Our goal was to study the barriers to usage in this rapidly growing segment and how these barriers can be overcome to design meaningful health interventions.

Methods: Starting with secondary research, our team conducted primary research interviews in a group of 250 young families (pregnancy or an infant in the family) within six diverse low income communities in Mumbai and Delhi. The surveyed population represents the global segment of the next billion emerging mobile users. The hypotheses generated from our research were used for rapid prototype development, testing and iteration over two rounds with similar users in Mumbai. Prototype development was informed by learnings from commercial apps used by emerging mobile users that address patchy connectivity, low data speeds and cost conscious consumers. The prototype testing included qualitative and quantitative methods.

Results: Our primary research showed rapidly increasing and recent ownership of internet enabled phones (83\%) in our surveyed population. 56\% of users had acquired their smartphone in the last year and only 10\% had owned a smartphone for more than 2 years. Phone ownership had a strong gender bias with only $39 \%$ women owned phones compared with $85 \%$ in men. Smartphone ownership was linked to monthly house income, rising from 35\% ownership in households earning less than 20,000 INR to $90 \%$ in households earning 20,000-40,000 INR. Phone ownership across the same income segments increased dramatically in digitally ready neighborhoods that had a superior infrastructure and connectivity. The main reasons for not using the internet were lack of knowledge (80\%), cost (57\%), lack of local language content (39\%) and lack of motivation (35\%). Emerging mobile users were drawn to the internet primarily for entertainment (95\%), social networking (82\%), and online gaming (74\%). Only $18 \%$ of the population was using internet to seek health care related information, and when they did, digital health information was reported as least reliable, with close to $90 \%$ of respondents ranking them lowest on the reliability scale. Our users were more likely to respond to the test mobile app when it was data light, transparent, and allowed for offline viewing and sharing. Behaviorally, reducing cognitive load significantly allowed users to make confident decisions. This meant creating linear user journeys, minimizing screen choices and nudging users towards specific messages using a combination of rewards and loss aversion techniques. Even though literate, our users responded overwhelmingly to visual and video content than to written text. Finally, activating the user journey on the app was much more powerful when done through a trusted community resource.

Conclusions: Slimming down existing health apps won't address the unique needs of emerging mobile users. Designing connected health interventions for the next billion mobile users requires multi-disciplinary teams to design content experiences and user journeys rooted in local ecosystems and tailored to the users' unique sensibilities.

(iproc 2018;4(2):e11778) doi: $\underline{10.2196 / 11778}$ 


\section{KEYWORDS}

emerging mobile users; design; user experience; connected health

Edited by T Hale; this is a non-peer-reviewed article. Submitted 02.08.18; accepted 30.08.18; published 17.09.18.

Please cite as:

Ganju A, Saharan S, Lin Fabiano A, Lee L

Designing Connected Health Interventions for Emerging Mobile Users

iproc 2018;4(2):e11778

URL: http://www.iproc.org/2018/2/e11778/

doi: $\underline{10.2196 / 11778}$

PMID:

(C)Aakash Ganju, Sumiti Saharan, Alice Lin Fabiano, Lily Lee. Originally published in Iproceedings (http://www.iproc.org), 17.09.2018. This is an open-access article distributed under the terms of the Creative Commons Attribution License (https://creativecommons.org/licenses/by/4.0/), which permits unrestricted use, distribution, and reproduction in any medium, provided the original work, first published in Iproceedings, is properly cited. The complete bibliographic information, a link to the original publication on http://www.iproc.org/, as well as this copyright and license information must be included. 